\title{
Liderança no contexto da nova administração pública: uma análise sob a perspectiva de gestores públicos de Minas Gerais e Rio de Janeiro*
}

\author{
Fátima Bayma de Oliveira** \\ Anderson de Souza Sant'Anna*** \\ Samir Lofti Vaz****
}

SumÁrio: 1. Introdução; 2. Fundamentação teórica; 3. Aspectos metodológicos; 4. Apresentação e análise dos resultados; 5 . Considerações finais.

Summary: 1. Introduction; 2. Theoretical framework; 3. Methodological aspects; 4. Results and analysis; 5. Final remarks.

Palavras-chave: administração pública; liderança; competências do gestor público; gestão por resultados.

KEY WORDs: public administration; leadership; skills of public managers; managing for results.

Novas incursões orientadas à modernização do estado, centradas na adoção de modelos de gestão pública que visam enfatizar a noção de resultado, assim como de

\footnotetext{
* Artigo recebido em maio 2010 e aceito em ago. 2010.

** Doutora em educação, mestre em administração, com especialização na França e na Bélgica. Professora titular da Fundação Getulio Vargas nos cursos de doutorado, mestrado, especialização e graduação em administração. Endereço: Praia de Botafogo, 190, Sala 531 - Botafogo — CEP 22250-900 — Rio de Janeiro, RJ, Brasil. E-mail: fbayma@fgv.br.

*** Doutor em administração pela Universidade Federal de Minas Gerais. Professor da Fundação Dom Cabral e do Programa de Pós-Graduação em Administração da Pontifícia Universidade Federal de Minas Gerais. Coordenador do Núcleo Vale de Desenvolvimento de Liderança, da Fundação Dom Cabral. Endereço: Av. Princesa Diana, 760 - Alphaville Lagoa dos Ingleses - CEP 34.000000 - Nova Lima, MG, Brasil. E-mail: anderson@fdc.org.br.

$* * * *$ Mestrando em administração pela Universidade de São Paulo (FEA/USP). Graduado em administração pela Universidade Federal de Minas Gerais. Pesquisador associado do Núcleo Vale de Desenvolvimento de Liderança, da Fundação Dom Cabral. Endereço: Av. Princesa Diana, 760 — Alphaville Lagoa dos Ingleses — CEP 34.000-000, Nova Lima, MG, Brasil. E-mail: samirvaz@ usp.br.
} 
instrumentos gerenciais típicos do management, leadership e do mundo corporativo vêm caracterizando a gestão pública brasileira. Nessa perspectiva, há de se salientar iniciativas como as dos estados de Minas Gerais, por meio de seu programa de choque de gestão, e do Rio de Janeiro. Tendo por base tais movimentos e experiências, novas questões emergem e demandam ser melhor compreendidas. A partir da análise de relações entre iniciativas associadas ao movimento em torno da chamada nova administração pública e o construto liderança, este trabalho tem como propósito central investigar, a partir de levantamento empírico de dados realizado junto a ocupantes de posições chave no setor público dos governos de Minas Gerais e Rio de Janeiro, temas, questões e desafios que emergem de tais iniciativas, assim como suas implicações sobre a demanda por novos perfis de liderança e formas de seu desenvolvimento. Com o auxílio do software de tratamento qualitativo NVivo 8 foi possível agrupar os principais temas e desafios identificados em torno das relações entre nova administração pública e liderança. O estudo permitiu, também, identificar um elenco de atributos de competências requeridas ao gestor e líder do setor público.

Leadership in the context of new public management: an analysis from the perspective of public managers of Minas Gerais and Rio de Janeiro

New schools of thought targeted at the modernization of the state and centered on the adoption of public management models designed to emphasize the notion of outcome as well as of managerial tools typical of management, leadership and the corporate world have characterized public management in Brazil. From this perspective, initiatives such as those of the states of Minas Gerais and Rio de Janeiro, with their modernization of state programs should be pointed out. Based on such experiences and movements, new issues emerge and demand to be better understood. From the analysis of the relations between initiatives associated to the movement around the so-called new public management and the category leadership, this study's main goal is to investigate, using empirical data collection conducted with occupants of key positions in the public sector of both Minas Gerais and Rio de Janeiro's governments, themes, issues and challenges that emerge from such initiatives, as well as their implications on the demand for new kinds of leadership and ways of its development. With the help of the qualitative data research software NVivo 8, it was possible to group the main issues and challenges identified around the relations between public administration and new leadership. The study also allowed us to identify a list of competency attributes required of the manager and leader of the public sector.

\section{Introdução}

Um traço parece caracterizar a gestão pública brasileira contemporânea: a adoção de conceitos, discursos e práticas gerenciais típicas do mundo corporativo. Criatividade, postura empreendedora, inovação gerencial, gestão por resultados, contratos de gestão, gestão por competências são alguns dos ter- 
mos e expressões que, paulatinamente, aderem ao vocabulário cotidiano das diversas instâncias da gestão pública nacional.

Influenciadas pela disseminação de concepções neoliberais, calcadas nas noções de estado mínimo e gestão por resultados, as instituições públicas cada vez mais aparentam aderirem à lógica de mercado, concebendo o cidadão como cliente e adotando novas políticas e práticas de gestão, conforme disseminadas na esfera privada.

No Brasil, tal fenômeno ganha espaço a partir do processo de redemocratização, nos anos 1980, alimentado pela difusão de discursos que enfatizam uma ampla crise da administração pública, a qual demandaria para seu equacionamento novos paradigmas de gestão, capazes de superarem as estruturas centralizadas, as hierarquias formais e os sistemas de controle tayloristas prevalentes (Bresser Pereira, 1996). Em outros termos, acentua-se a necessidade de superação dos tradicionais modelos de gestão pública, burocráticos e autocráticos, por meio da difusão de novos sistemas, mais democráticos, participativos e meritocráticos (Bresser Pereira, 1996, 1997; Martins, 1997; Prestes Motta, 2007).

Ademais, disseminava-se, na esteira do movimento em torno da qualidade total, a relevância de as organizações públicas considerarem com maior atenção seus clientes e diferentes stakeholders, rompendo corporativismos e privilégios históricos. Mesmo reconhecendo que o objetivo das organizações vinculadas ao estado não deveria ser o lucro, demandava-se maior eficiência e transparência quanto ao valor que, efetivamente, agregavam à sociedade.

Nesse sentido, as organizações públicas se veem pressionadas a reverem suas estruturas e dinâmicas de funcionamento, a fim de otimizarem seus processos e rotinas, assegurando melhor desempenho e resultados mais efetivos (Pablo et al., 2007). Como resultante, a demanda por reformas no setor passa a se constituir como importante elemento da agenda política nacional, inserindo-se de forma sistemática nos discursos das lideranças e gestores públicos, que cada vez mais deveriam assumir um perfil empresarial e gerencial (Saraiva Silva, 2002).

Nos anos 1990, tal debate se amplifica, ganhando espaço o movimento em torno de uma nova administração pública, que acelerasse a ruptura de traços seculares do setor, fundamentados no tradicionalismo (Faoro, 1964), personalismo (Prestes Motta, 2007) e patrimonialismo (Bresser Pereira, 1996; Faoro, 1964). Como resultado, downzing, privatização, reengenharia de processos, desburocratização se configuram em conceitos que marcariam diversas ações de governo, nesse período. 
Cabe destaque, nesse contexto, estudos desenvolvidos por Bresser Pereira $(1996,2007)$, assim como sua atuação na defesa da reforma do Estado como ministro da Administração e Reforma do Estado, do governo Fernando Henrique Cardoso. Para ele, inclusive, a classificação de iniciativas vinculadas à chamada nova administração pública como de cunho neoliberal apresentava-se indevida, assim como indevido seria se rotularem como tal iniciativas, na mesma direção, promovidas, por exemplo, por países escandinavos. Ao contrário, para o professor e então ministro, o tema do gerencialismo como característica da administração pública contemporânea implicava, de fato, o afastamento de premissas neoliberais, na medida em que se volta para a constituição de um Estado forte e progressista.

A administração gerencial, para esse autor, derivava na formação de profissionais que "pensem como lideranças capazes de perceber problemas, buscar recursos, criar soluções e estabelecer redes sociais. Portanto, um perfil mais gerencial, mais politizado e menos tecnocrático diferenciando-se, assim, do administrador público tradicional" (Fonseca, 2008:12).

Mais contemporaneamente, registram-se novas incursões orientadas à modernização do Estado, centradas em modelos de gestão pública que enfatizam a noção de resultado e a adoção de instrumentos gerenciais típicos do management, conforme amplamente difundidos e incorporados pelas grandes organizações privadas. Entre essas, há que se salientar iniciativas como as dos estados de Minas Gerais, por meio de seu programa de choque de gestão, e do Rio de Janeiro.

Tendo por base tais movimentos e experiências, novos temas emergem e demandam ser melhor compreendidos. Afinal, que novas problemáticas e desafios tais iniciativas incorporam à agenda de preocupações estratégicas de líderes e gestores do setor público brasileiro? Que novos perfis e competências de liderança e gerenciais passam a ser demandados? Se e como desenvolvê-los?

Partindo, portanto, da análise de relações entre iniciativas associadas à chamada nova administração pública e o construto liderança, este trabalho tem como propósito central investigar, a partir de levantamento empírico de dados realizado junto a executivos ocupantes de posições chave no setor público dos governos de Minas Gerais e do Rio de Janeiro, os principais temas e desafios que caracterizariam iniciativas vinculadas à noção de nova administração pública, assim como suas implicações sobre a demanda por novos perfis de liderança e formas de seu desenvolvimento.

Considerando o objetivo central do estudo, seus objetivos específicos podem ser assim descritos: 1. identificar temas e desafios à nova administração pública, a partir das experiências adotadas pelos governos estaduais alvos deste estudo; 2 . investigar definições e atributos de liderança requeridos 
aos líderes e gestores públicos, tendo em vista o novo contexto do setor e as iniciativas de modernização do estado analisadas; 3. propiciar subsídios para o delineamento de novos temas chave de pesquisa e de desenvolvimento de liderança no estágio atual do setor.

Como referencial teórico cabe salientar revisão de literatura que visa delinear um panorama do movimento em torno da noção de nova administração pública, assim como das especificidades associadas ao construto liderança e seu desenvolvimento, tendo por base o setor e seu atual contexto.

Em termos metodológicos, a pesquisa que subsidiou os resultados deste estudo pode ser caracterizada como de natureza qualitativa e caráter descritivo. Quanto à coleta de dados, baseou-se na realização de entrevistas semiestruturadas e em profundidade junto a sete executivos do setor público brasileiro, ocupantes de posições estratégicas nas administrações dos estados de Minas Gerais e do Rio de Janeiro e com papel protagônico, nos programas de modernização da gestão de seus governos. Para o tratamento dos dados adotou-se a técnica de análise de conteúdo por categoria, realizada com o auxílio do software de tratamento qualitativo de dados NVivo 8.

No que tange à sua relevância, o estudo justifica-se, em termos teóricos, ao ampliar os estudos sobre a temática da liderança e de sua configuração no âmbito do setor público brasileiro, considerando as transformações associadas, em especial, à tônica que vem sendo atribuída à incorporação de políticas e práticas de gestão, típicas do management e da leadership, de inspiração norte-americana. Justifica-se, ainda, ao propiciar subsídios a problematizações e, nessa direção, ao delineamento de novos temas e linhas de pesquisa sobre a liderança na esfera pública e do setor em análise. Em termos práticos, sua relevância assenta-se na possibilidade de elementos que venham a subsidiar análises mais críticas, que contemplem implicações, a longo prazo, das políticas, práticas e instrumentos de gestão pública que vêm sendo incorporados, a partir dos pressupostos da nova administração pública.

Isto posto, apresenta-se, a seguir, a fundamentação teórica que subsidiou o desenho da pesquisa, a construção do roteiro de entrevistas, assim como a análise e discussão dos dados obtidos.

\section{Fundamentação teórica}

\subsection{O movimento em torno da nova administração pública}

Embora pareçam evidentes as diferenças no que se refere às características requeridas à liderança nos setores público e privado, a administração públi- 
ca brasileira passa a incorporar, especialmente a partir de fins da década de 1980, início dos anos 1990, conceitos de gestão bastante similares aos observados em grandes corporações empresariais do pós-ruptura do ciclo virtuoso do fordismo (Lipietz, 1985), no contexto de um movimento que vem sendo denominado de nova administração pública.

Em linhas gerais, com os processos de reestruturação produtiva pós era de ouro do capitalismo, o Estado perde sua relevância na qualidade de elemento chave na dinâmica de produção e regulação que definiria os rumos da macroeconomia, nos países centrais, no período que se estenderia entre o final da Segunda Grande Guerra Mundial até meados dos anos 1970, com a crise do petróleo. Perdendo seu status de agente produtor e de mediação das relações de trabalho, ao Estado é requerido um novo papel: o de Estado mínimo, devendo atuar não mais que na instância da regulação das transações econômicas - preferencialmente, via agências reguladoras - e como facilitador de políticas de cunho neoliberal.

Ao se vincular a essas novas demandas, passa-se a requer do Estado novos sistemas de gestão, capazes de respostas mais efetivas às necessidades do novo estágio de desenvolvimento do capitalismo. Como decorrência, registram-se severas críticas aos modelos prevalentes de administração pública, assim como intensa mobilização política e ideológica para a construção e legitimação de um novo modelo de gestão pública, calcado em conceitos mais modernos, tais como inovação gerencial, autonomia administrativa, descentralização, delegação de autoridade (Bresser Pereira, 1997; Silva, 1994).

Tal movimento vai contar, por seu escopo, com forte influência dos modelos de gestão de instituições privadas, notadamente anglo-americanas, considerados mais aptos ao novo contexto. Valores como eficiência, foco em resultados, valorização do espírito empreendedor são, então, continuamente, incorporados ao vocabulário dos líderes e gestores públicos. Igualmente, a noção de desempenho individual é revisitada, por meio de avaliação de desempenho, remuneração variável e gestão por competências (Prestes Motta, 2007:94).

Em uma análise sobre a evolução da administração pública e seus movimentos contemporâneos, em nível mundial, Terry (1998) caracteriza o momento atual a partir de dois princípios centrais: o liberalismo gerencial (liberation management) e o gerenciamento orientado ao mercado (market driven management).

Os proponentes do liberalismo gerencial defendem que os gestores públicos são bem intencionados e qualificados, porém, o sistema governamental é ineficiente na captura de tais competências, em função de sua burocracia estrutural. Diante disso, propõem maior autonomia na atuação dos gestores 
públicos e, em paralelo, a defesa de maior liberdade desses profissionais em relação ao aparato burocrático do Estado. Para eles, a autonomia e a liberdade são possíveis por meio de ações de desregulamentação interna dos mecanismos de gerenciamento dos órgãos públicos e pela descentralização dos processos administrativos, viabilizados por meio, por exemplo, de dispositivos como orçamentos e contratos de gestão (Terry, 1998). Adotando uma perspectiva eminentemente racional-gerencialista, tal visão liberal da administração pública se destaca pela ênfase no resultado e na relação custo/benefício de suas iniciativas e programas (Martins, 1997).

Já no âmbito do gerenciamento orientado ao mercado têm-se como elementos fundamentais a valorização da competição e da eficiência. Tal abordagem preconiza a criação de mercados internos para os serviços públicos, capazes de estimular a competição por recursos, a melhoria do desempenho, a redução de custos e o incentivo à busca contínua por maiores níveis de eficiência. Igualmente, a adoção de lógica, política, práticas e instrumentos de gestão do setor privado são enfatizados (Terry, 1998).

Sustentado por tais princípios, o autor destaca o movimento em torno da construção de um neogerencialismo (neo-managerialism). A ideia subjacente é que os gestores públicos deveriam ser inovadores oportunistas, motivados por interesses pessoais e, como tomadores de riscos, aproveitar-se-iam de informações e situações específicas para promoverem mudanças radicais. Em suma, deveriam assumir o papel de líderes empreendedores (Terry, 1998). A ênfase em tal estilo de liderança, todavia, receberá inúmeras críticas. A principal delas de defender características que estimulam o caráter manipulador e oportunista.

Como contraposição ao neogerencialismo, base de sustentação do modelo liberal de administração pública minimalista, defende-se o delineamento de uma administração pública ativista. Tal proposta, também, não é poupada de críticas, notadamente por insistir na transformação da gestão pública em empresarial, ignorando a dimensão política do Estado e reduzindo seu propósito final à utilidade de mercado (Martins, 1997:65). De forma similar, não deixa claro o papel dos agentes e lideranças no processo.

\subsection{A nova administração pública brasileira: implicações sobre a noção de liderança}

Os movimentos em torno do liberalismo gerencial, do gerenciamento orientado ao mercado, do neogerencialismo e de uma administração pública ativista encontraram, no Brasil, terreno fértil, especialmente considerando os debates 
sobre o papel do Estado e da administração pública, no decorrer do processo de redemocratização do país, no final da década de 1980. Afinal, ainda que se tenham desenvolvido novas práticas e alardeado expectativas quanto à modernização do Estado e da administração pública, muitas das características tradicionais perduravam (Prestes Motta, 2007). Uma dessas características é o personalismo, que segundo Prestes Motta (2007) caracteriza o poder como centrado na figura de um líder, um dirigente e não como resultado da gestão de recursos e relações inerentes às estruturas organizacionais.

O personalismo, como analisado por Prestes Motta (2007), apresenta relação direta com particularidades históricas da gestão das organizações públicas brasileiras. Os dirigentes, na origem, prepostos de líderes políticos, tendiam a inserir suas opções como fatores diferenciadores e, em decorrência, a instaurarem processos decisórios autocráticos e centralizados, não raro baseados em uma racionalidade meramente política, centrada em projetos pessoais, desconsiderando ações de gestões anteriores e/ou implicações sobre as futuras administrações.

Diante disso, a modernização da gestão deveria, segundo esse autor, problematizar os diversos aspectos subjacentes à noção de liderança no setor, bem como dispositivos para o desenvolvimento de novos grupos de poder. Para ele, não bastariam ações cosméticas: seria necessário colocar em evidência os fundamentos e princípios da gestão e da liderança de tais processos (Prestes Motta, 2007).

Tais considerações encontram, desse modo, convergências com pressupostos de Martins (1997), que reconhece, na dicotomia entre política e administração, traço distintivo do processo de modernização da administração pública brasileira. Adotando uma perspectiva otimista, mesmo ciente do caráter tradicionalmente ortodoxo das organizações públicas, o autor aponta potencialidades das propostas associadas à construção de uma nova administração pública brasileira. Ressalta, todavia, que o debate sobre alternativas emergentes não se verificava com o vigor e aprofundamento necessários, tanto no plano acadêmico, quanto político.

Especialmente no plano acadêmico, o autor destaca que, no Brasil, a modernização da administração pública — envolvendo o movimento em torno de uma nova administração pública — traz consigo ainda poucos debates sobre mudanças em aspectos culturais associados à gestão no setor, principalmente no que tange à temática da liderança e suas implicações sobre o desempenho de suas instituições. Na perspectiva desse autor, se a liderança é um construto ou variável em muitos casos incompreendida, inconclusiva, e mesmo contraditória, é porque apresenta complexidades ainda pouco exploradas e, possivel- 
mente, ainda mais amplas quando considerado o território das organizações públicas.

A proposta de novos mecanismos de gestão pública deveria, portanto, segundo Martins (1997), vir acompanhada de análises mais profundas sobre o construto da liderança, considerando tanto as especificidades do fenômeno no micro, meso e macro contextos do setor, quanto suas mais variadas abordagens: de traços, comportamental, situacional, cultural e mesmo seu caráter carismático ou transformacional.

\subsection{Especificidades da liderança na esfera pública}

A elevada ênfase em estudos envolvendo o setor privado e, portanto, a carência de estudos mais amplos e críticos sobre a temática da liderança no setor público torna a demanda por contribuições teóricas sobre o tema, nesse âmbito, ainda mais significativa. Essa escassez de estudos talvez possa estar associada ao imaginário de que burocracias são movidas por forças que se encontram além do controle de líderes (VanWart, 2003).

Para Hooijberg e Choi (2001), enquanto líderes públicos devem concatenar inúmeros objetivos, com diferentes racionalidades e interesses, os líderes do setor privado tenderiam a ter objetivos mais claros. Afinal, encontramse focados em um propósito central: o lucro, mais facilmente mensurável, por meio de indicadores econômico-financeiros. Além de dificuldades de se mensurar o desempenho dos líderes do setor público, soma-se o turnover desses agentes, quer em função de limites de tempo no cargo, quer por mudanças administrativas e políticas frequentes. Agrega-se a isso, ainda, a estabilidade no emprego experimentada por grande parte — ou mesmo a totalidade — de seus liderados.

Ainda para esses autores, as leis, controles e regulamentações presentes na esfera pública, reduzem a discricionariedade de seus líderes. Na perspectiva de Hooijeberg e Choi (2001), tal aspecto abrange a amplitude de atividades e o nível de autonomia de ação desses líderes, podendo resultar em comportamentos inibidos e limitados. São alguns desses fatores inibidores: os cargos com funções demasiadamente explícitas e documentadas; deveres, autoridade e prestação de contas codificadas e o reduzido controle e autonomia sobre os recursos. Sob a ótica dos liderados, tais aspectos atuariam como substitutos da liderança. Em suma, para esses autores, diferentes níveis de discricionariedade atribuídos aos gestores do setor público e privado resultariam em formas particulares de liderança (Hooijeberg e Choi, 2001). 
Com o intuito de verificar tais pressuposições, Hooijeberg e Choi (2001) realizaram estudo comparativo envolvendo instituições públicas e privadas visando investigar a relação entre comportamentos ou papéis do líder e a eficácia de sua atuação. Os resultados indicam que, em comparação com agentes privados, os gestores públicos percebem menor associação entre liderança orientada a tarefas e eficácia. Para eles, a eficácia apresentou-se mais associada a estilos de liderança de monitoração/facilitação. Tais estilos, por sinal, mais orientados para o ambiente interno das organizações. Merece destaque, ainda, a relação obtida entre eficácia e senioridade dos líderes, percebida de forma positiva em órgãos públicos e negativa em ambientes privados (Hooijeberg e Choi, 2001).

De forma similar aos achados de Hooijeberg e Choi (2001), Pablo et al. (2007) também destacam o enfoque das organizações do Estado como mais amplamente baseado em seu ambiente interno. Isso, na visão desses autores, fruto da necessidade de atendimento às demandas de públicos específicos, não raro bastante corporativistas, e da ausência do pressuposto do lucro. Tal aspecto estaria, ainda, acompanhado pelo fato de que, especialmente na esfera pública, o desempenho é influenciado por múltiplas ações individuais, nem sempre formalmente coordenadas. Em consequência, o desenvolvimento da estratégia deveria considerar, de forma mais ampla, recursos internos e os diversos atores sociais envolvidos (Pablo et al., 2007).

Esses autores investigam empiricamente o papel de líderes no contexto de uma organização de saúde pública, a qual vivenciou intenso processo de redução de custos e busca por maior eficiência na utilização de recursos. A partir da análise desse caso, observam que é esperado das lideranças criarem oportunidades para que as pessoas adotem posturas mais proativas e realizem iniciativas em prol do desenvolvimento organizacional. Soma-se a isso a importância de encorajarem ações que estimulem relacionamentos de confiança, suportando as iniciativas individuais (Pablo et al., 2007).

Outra pesquisa aplicada no ambiente de uma organização pública, conduzida por Saraiva Silva (2002), contribui com outras importantes reflexões sobre aspectos da liderança em tal contexto. Buscando investigar relações entre o ambiente burocrático de uma organização pública e sua cultura organizacional, o autor destaca a rigidez burocrática como fator crítico de desajuste e conflito. Além disso, na medida em que muito dependentes de normas e tendendo a processos de acomodação de interesses, os líderes e liderados acabavam por vivenciar inúmeros sentimentos negativos, tais como desestímulo, instabilidade e resistência a mudanças, com fortes implicações sobre a ambiência organizacional. 
Tendo por base tal referencial, este trabalho tem como propósito central ampliar o debate, agregando às pesquisas no campo, novos temas e questões que emergem de iniciativas de modernização do Estado e da gestão pública, vivenciados pelos estados do Rio de Janeiro e de Minas Gerais. Esse último, alçado à categoria de referencia nacional, por meio de seu programa de choque de gestão.

Em linhas gerais, o choque de gestão se constitui em uma política de estado, proposta pelo governo de Minas Gerais, visando a promoção do desenvolvimento mediante a reversão do quadro de déficit orçamentário então vivenciado pelo estado - por meio da redução de despesas - , a reorganização e modernização do aparato institucional da sua esfera de abrangência e a implementação de novos modelos de gestão.

No âmbito do choque de gestão, medidas emergenciais foram tomadas, fundamentalmente de caráter estruturador e operacional, objetivando a redução imediata de custos e a efetivação de um novo desenho institucional, mais moderno e dinâmico. A médio e longo prazos, o projeto contempla a gestão para obtenção de resultados baseados na qualidade e na produtividade, mediante critérios de incentivos que induzam o maior comprometimento dos atores responsáveis. Por outro lado, também prevê o investimento na capacitação do servidor público e a adoção de novos modelos de parcerias públicoprivadas, que possibilitem a oferta de melhores serviços aos cidadãos.

A aplicação dos métodos utilizados no choque de gestão foi orientada por empresa externa de consultoria, com vasta experiência no setor empresarial, que ao longo do trabalho orientou os gestores e servidores envolvidos e disponibilizou sistemáticas e instrumentos de análise e acompanhamento. Iniciativas semelhantes foram desenvolvidas em outros estados e em diversas prefeituras do país.

\section{Aspectos metodológicos}

A pesquisa que subsidiou os resultados apresentados neste artigo pode ser classificada como de natureza qualitativa e caráter descritivo. Os dados primários foram obtidos por meio de entrevistas semiestruturadas, realizadas junto a sete executivos ocupantes de posições estratégicas na gestão pública dos governos estaduais de Minas Gerais e do Rio de Janeiro - secretários de estado, subsecretários e assessores especiais de áreas de gestão e planejamento. A opção por estes sujeitos de pesquisa derivou do papel protagônico 
desempenhado por eles junto a iniciativas fundamentadas em pressupostos da chamada nova administração pública.

Cabe mencionar que as entrevistas foram gravadas - totalizando aproximadamente 11 horas de gravação - , transcritas e os dados, posteriormente, submetidos à técnica de análise de conteúdo por categoria (Flick, 2009), com o auxílio do software de tratamento qualitativo de dados NVivo 8.

Por meio deste software buscou-se, primeiramente, a geração exaustiva de categorias mutuamente exclusivas (Miles et al., 1994), representadas por um conjunto de códigos referentes a diversas impressões, críticas e fatores convergentes sobre o tema. Desse conjunto de códigos, descritos como de primeira ordem, foram estabelecidas relações de proximidade, causa e efeito, o que possibilitou a identificação de categorias de segunda ordem, baseadas em descrições mais abrangentes (Gioia e Thomas, 1996), as quais se constituíram nos principais temas (dimensões chave) em liderança, segundo os pesquisados.

\section{Apresentação e análise dos resultados}

A partir do conjunto dos dados obtidos junto às lideranças e gestores públicos pesquisados pôde-se agrupar as principais questões e desafios contemporâneos em torno da gestão pública brasileira e o construto liderança em cinco grandes temas (dimensões chave): O estágio atual do setor público brasileiro: a tônica na eficiência e em resultados; Desafios da transição para uma nova administração pública; Incorporação de políticas e práticas de gestão inspiradas no setor privado; Especificidades da liderança na esfera pública.

\section{O estágio atual do setor público brasileiro: a tônica na eficiência e em resultados}

Em relação ao estágio atual do setor público brasileiro, as percepções dos entrevistados apontam para um "significativo desnível no desenvolvimento da máquina pública, em suas diferentes esferas". Em nível municipal, salientam que "apenas poucas dezenas, ou mesmo unidades de municípios, merecem destaque pela modernização e mudanças em suas práticas organizacionais". Em âmbito estadual, de forma similar, apontam que "enquanto alguns estados se engajam na busca por maior eficiência na gestão do uso de recursos, na grande maioria, ainda prevalecem organizações cuja realidade administrativa mantém características tidas como ultrapassadas". Já na esfera da União, des- 
taca-se que "a mesma passou a adotar, a partir do governo Lula, uma orientação para o aumento do tamanho da máquina e da participação do Estado federal nas demais instâncias". Não que tal perspectiva tenha "abandonado a busca por um Estado eficiente, introduzida já em gestão anterior". Mas o atual enfoque "se permite abdicar, em partes, de tal eficiência, pelo relativo aumento na atuação pública federal, em especial devido à melhoria na situação econômica do país, o que tem propiciado forte retomada dos investimentos federais, conforme é possível se observar por meio das iniciativas do Programa de Aceleração do Crescimento (PAC)", observa um dos respondentes.

Os entrevistados destacam, ainda, uma série de fatores que têm impulsionado, nos últimos tempos, maior aporte de recursos no setor público, assim como fomentado uma utilização mais eficiente de tais recursos e a oferta de serviços de melhor qualidade à sociedade. Entre eles, salientam a atração de grandes eventos, tais como fóruns internacionais, encontros de cúpula, olimpíadas, copa do mundo, entre outros. Para os entrevistados, tais eventos têm estimulado a capacidade dos agentes públicos mobilizarem reformas em suas políticas e práticas de gestão. Para eles

essas pressões "de fora" têm-se constituído em fontes necessárias à modernização da gestão pública nacional, haja vista, por exemplo, as exigências que derivam de agentes internacionais de fomento, como Banco Mundial e Banco Interamericano, que requerem reformas ao país e às entidades públicas, de forma a nos tornarmos elegíveis à captação de recursos e eventos.

Somam-se a isso as pressões dos meios de comunicação e da opinião pública, dada a maior conscientização dos cidadãos, o que, igualmente, "colabora para a tendência de maior participação e cobrança por resultados e eficiência por parte da gestão pública".

Diante de tal contexto, os relatos destacam maior pressão, quer da sociedade, quer dos próprios líderes do setor, quanto à adoção de princípios mais afins à noção preconizada pelo movimento em torno da nova administração pública. Isto é, perspectivas mais "gerencialistas, com modelos de administração caracterizados por uma burocracia evoluída, baseada na gestão por resultados". Para a grande parte dos respondentes, os últimos cinco anos "reportam intensos esforços em prol de inovações na administração pública nacional, com reformas abrangendo melhor gestão fiscal, revisão de sistemas, processos e arcabouços jurídicos".

Motivados por casos tidos como de "sucesso", em especial o chamado choque de gestão, de Minas Gerais, a gestão pública, na perspectiva dos res- 
pondentes "entra na pauta da política nacional, tornando-se, inclusive, bandeira levantada por candidatos em campanhas eleitorais", indicando tendências quanto à intensificação e difusão desse movimento para outros estados e instâncias da administração pública.

\section{Desafios na transição para uma nova administração pública}

Não obstante relatos indicarem o estágio atual do setor público como "pressionado por reformas que visam maior desempenho e eficiência da máquina pública", diversos desafios ao "processo de transição para uma nova administração pública brasileira" são apontados.

Um desses desafios é a dissociação entre Estado e sociedade. Muito embora uma maior participação popular, "observa-se uma cobrança e pressão popular que necessitaria ser ampliada". Para grande parte dos entrevistados uma atuação mais ativa e organizada da sociedade civil se constitui em "elemento fundamental para maior autonomia e liberdade na atuação de gestores públicos" e em um poder discricionário capaz de se refletir em maior qualidade e eficiência de suas atuações.

Outro desafio relatado são os obstáculos à manutenção dos "avanços obtidos pelas reformas adotadas". Isso, em decorrência das alternâncias de poder e duração dos mandatos políticos: "períodos de apenas quatro ou oito anos são, na verdade, insuficientes à consolidação dos novos modelos. É preciso uma mentalidade de eficiência e resultados que extrapole a duração dos mandatos políticos". Além disso, salientam que algumas posições, como de prefeitos e governadores, estão sujeitas a "inúmeras pressões de cunho eleitoral, o que restringe, em parte, a capacidade dos mesmos em coordenar as mudanças necessárias".

As barreiras também se referem à escassez de recursos vivenciada por incontáveis organizações públicas, ao longo do país, em suas mais diferentes esferas: "seja por razões políticas, ou não, os investimentos são utilizados de maneira ineficiente, sustentando, em alguns casos, estruturas, departamentos ou organizações tidos como desnecessários", salienta-se.

A partir dos relatos obtidos, constata-se, todavia, ser "na cultura dos gestores públicos onde reside parcela significativa dos entraves ao novo modelo de administração proposto". Para eles, o padrão de gestão burocrática ainda prevalece, levando a inércias na atuação de tais profissionais, os quais, em grande parte, "ainda não encontram benefícios na reorientação a favor da gestão aos moldes privados". 
Nessa direção, para a maior parte dos entrevistados, a "administração de pessoas constitui importante desafio neste contexto, considerando que a cultura é formada a partir de valores, processos, normas e sistemas já estabelecidos e propagados no setor". Para vários dos respondentes,

o servidor público está habituado a políticas e planos de carreira fundamentados na estabilidade e na remuneração fixa. Os programas de avaliação de desempenho e remuneração variável, embora desejáveis para promover a obtenção de resultados coletivos e individuais, conforme ocorre na esfera privada, encontram profundas resistências às suas implantações na esfera pública.

Diante disso, apontam a mudança do padrão de estabilidade e remuneração fixa como fatores fundamentais de "motivação e correções de funcionários pouco eficientes".

Os processos de recrutamento e seleção, por meio de concursos públicos, são, também, amplamente criticados. Os entrevistados argumentam que em muitos casos a modernização do Estado depende de projetos com "maior nível de sofisticação, mais complexos e acelerados, que deveriam ser coordenados por pessoas de alto nível, com perfil executivo". O próprio timing da contratação, via concursos, e o treinamento necessário aos contratados inviabiliza, em parte, segundo os respondentes, tais iniciativas.

A atual forma de contratação de pessoas apresenta-se, adicionalmente, "contrária à gestão baseada em competências, uma vez que a realização de provas não permite que sejam analisadas características importantes das pessoas nesse novo contexto, a citar perfis e habilidades específicas". Destacam, desse modo, a relevância de mudanças nas práticas de recrutamento e seleção, orientadas para a "identificação de competências, conforme já amplamente difundido na esfera privada".

Em suma, os respondentes enfatizam que o novo perfil de gestor público requer indivíduos "cada vez mais qualificados e capazes de utilizar modernas práticas e tecnologias de gestão. Ele depende de novos conhecimentos, habilidades e atitudes, que se refletem em um novo elenco de competências individuais".

Ao longo das entrevistas foi possível, identificar diversas das "novas competências requeridas ao gestor público brasileiro", conforme sintetizadas no Quadro 1. 


\section{Quadro 1}

\section{Competências requeridas ao gestor público brasileiro contemporâneo}

\begin{tabular}{|c|c|}
\hline $\begin{array}{l}\text { Competências } \\
\text { requeridas ao } \\
\text { gestor público }\end{array}$ & Relatos \\
\hline $\begin{array}{l}\text { Conhecimento da } \\
\text { máquina pública }\end{array}$ & $\begin{array}{l}\text { "Assim, conhecimento de como funciona a máquina é importante. Ele não precisa } \\
\text { ter trabalhado especificamente. Vamos supor, a pessoa não precisa ter trabalhado } \\
\text { no estado, para desempenhar bem o papel de gestor no estado. Mas ela precisa ter } \\
\text { uma noção de como é que o jogo funciona em organizações públicas do executivo." }\end{array}$ \\
\hline $\begin{array}{l}\text { Conhecimento } \\
\text { jurídico }\end{array}$ & $\begin{array}{l}\text { "Um segundo aspecto: infelizmente, é conhecer bem a parte legal. Porque o que } \\
\text { acaba acontecendo? A gente percebe essa dissociação entre estado e sociedade, } \\
\text { e a sociedade não cobra. Então, outros meios começam a querer cobrar. E a } \\
\text { gente tem uma judicialização imensa no estado, ninguém se preocupa em } \\
\text { saber se é importante comprar um calendário ou não é importante comprar um } \\
\text { calendário. Está todo mundo preocupado se o processo de compra de calendário } \\
\text { está obedecendo à lei, nas suas vírgulas e nos seus pontos e vírgulas." }\end{array}$ \\
\hline $\begin{array}{l}\text { Capacidade de } \\
\text { promover o } \\
\text { envolvimento da } \\
\text { sociedade }\end{array}$ & $\begin{array}{l}\text { "Com relação no sentido mais macro, eu vejo que seria conseguir o envolvimento } \\
\text { da sociedade, de forma estruturada. Eu acho que o maior desafio é fazer esse } \\
\text { processo bem feito, o que significaria ele ser irreversível, mas ele ser organizado." }\end{array}$ \\
\hline $\begin{array}{l}\text { Capacidade de } \\
\text { lidar com o público }\end{array}$ & $\begin{array}{l}\text { "Por exemplo, na área de } \mathrm{RH} \text {, o maior problema que a gente teve foi de } \\
\text { habilidade, eles não tinham habilidades de lidar com o público, porque eles } \\
\text { estão ali para atender as pessoas. Eles conheciam profundamente a matéria, a } \\
\text { legislação de recursos humanos, mas não tinham habilidade em lidar com aquilo, } \\
\text { que era o público, que era o usuário dele." }\end{array}$ \\
\hline Objetividade & $\begin{array}{l}\text { "Ele [o gestor público] deve ser extremamente objetivo. Eu acho que a pluralidade } \\
\text { de assuntos pode levar a desvios. Então, eu acho que ele precisa ser bastante } \\
\text { objetivo, ter uma meta e buscar atingir aquilo que ele deseja." }\end{array}$ \\
\hline $\begin{array}{l}\text { Orientação para } \\
\text { resultados }\end{array}$ & $\begin{array}{l}\text { "Em outras palavras, o gestor que vai operar o estado, tem que ter em mente } \\
\text { que ele precisa atingir um resultado final. Ele tem que entender que ele é um } \\
\text { profissional que tem que apresentar um resultado, assim como é um profissional } \\
\text { do mercado. Então, o que eu vejo hoje que precisaria no setor público são as } \\
\text { pessoas mais preocupadas com o resultado e menos com os processos pelos } \\
\text { quais você alcança esse resultado." }\end{array}$ \\
\hline Perspectiva global & $\begin{array}{l}\text { "E assim, ele [o gestor público] tem que ser um gestor globalizado, ele tem que } \\
\text { estar sintonizado com as mudanças que estão ocorrendo, já que ele não pertence } \\
\text { mais ao estado, digamos assim, isoladamente. Mas, um estado que é conjunto de } \\
\text { uma Federação e muito mais federalizado do que nunca." }\end{array}$ \\
\hline $\begin{array}{l}\text { Relacionamento } \\
\text { interpessoal }\end{array}$ & $\begin{array}{l}\text { "E obviamente, em termos de habilidades assim, o interpessoal conta muito, } \\
\text { porque a nossa sociedade é muito relacionada. Então, tem que lidar, gerenciar o } \\
\text { pessoal, porque o seu pessoal é muito importante, até mesmo para trazê-los para } \\
\text { trabalhar junto." }\end{array}$ \\
\hline Visão sistêmica & $\begin{array}{l}\text { "Ou seja, um gerente, um líder, aqui na nossa administração, tem que ter uma } \\
\text { visão sistêmica voltada, obviamente, para a situação do país, do mundo, mas } \\
\text { focado na área pública. Mas, eu não tenho dúvida de que um líder e um gestor } \\
\text { da iniciativa privada também tenham que ter uma visão sistêmica, mas, com foco } \\
\text { já no negócio dele, já na área privada dele. Agora, eu acho que a gente está se } \\
\text { assemelhando, cada vez mais, às competências requeridas para a área privada e } \\
\text { para a área pública, em nível de gerente, de gestor, de liderança." }\end{array}$ \\
\hline
\end{tabular}

Fonte: Dados da pesquisa 
Pelos dados disponibilizados no Quadro 1 constata-se que as competências requeridas à atuação do novo gestor público, além de atributos mais gerais, amplamente observados no setor privado, compreendem, também, especificidades do setor, como o conhecimento da dinâmica e funcionamento da máquina governamental e o domínio de sua legislação. Ademais, revelam-se significativas as demandas por atributos de competência como postura globalizada, orientação para resultados e capacidade de mobilizar e promover o envolvimento e a participação de diferentes atores sociais.

\section{Incorporação dos modelos de gestão privada}

Mesmo diante dos desafios delineados, algumas "iniciativas e conquistas" são relatadas como fruto da "transição dos modelos tradicionais de gestão pública para um novo paradigma gerencial", diversas delas inspiradas e repletas de práticas discursivas do mundo corporativo. O Quadro 2 apresenta algumas dessas iniciativas e dispositivos.

Quadro 2

Iniciativas e projetos inspirados no setor privado

\begin{tabular}{|c|c|}
\hline Iniciativas e projetos & Caracterização \\
\hline $\begin{array}{l}\text { Projeto bolsões } \\
\text { organizacionais }\end{array}$ & $\begin{array}{l}\text { "Estão sendo criados departamentos e organizações que apresentam } \\
\text { processos e estruturas particulares, mais flexíveis, que buscam atender } \\
\text { a demandas pontuais do estado, a citar o planejamento e controle } \\
\text { orçamentário. Merecem destaque as Secretarias de Planejamento e Gestão, } \\
\text { nas quais as políticas e processos não seguem os padrões tradicionais do } \\
\text { governo." }\end{array}$ \\
\hline $\begin{array}{l}\text { Programa de } \\
\text { capacitação da } \\
\text { sociedade civil }\end{array}$ & $\begin{array}{l}\text { "Alguns estados estão se engajando em capacitar agentes da sociedade civil } \\
\text { para o controle sobre as ações públicas, em especial orçamentárias." }\end{array}$ \\
\hline $\begin{array}{l}\text { Gestão por projetos e } \\
\text { resultados }\end{array}$ & $\begin{array}{l}\text { "Sobretudo no estado de Minas Gerais, a gestão está se fundamentando } \\
\text { em chamados resultados finalísticos. Buscam-se definir metas e políticas } \\
\text { públicas cujos desempenhos possam ser mais bem avaliados por meio do } \\
\text { uso intensivo de práticas da gestão de projetos. O monitoramento sistemático } \\
\text { desses projetos tem garantido grandes ganhos em eficiência, principalmente } \\
\text { com relação à gestão fiscal." }\end{array}$ \\
\hline $\begin{array}{l}\text { Sistemas de } \\
\text { remuneração variável }\end{array}$ & $\begin{array}{l}\text { "Ao encontro dessa gestão por projetos e resultados já são adotados sistemas } \\
\text { de remuneração variável, vinculada à produtividade das pessoas. Esse } \\
\text { mecanismo é considerado importante meio de incentivo, ao premiar e punir } \\
\text { as pessoas de acordo com as metas individuais e coletivas." }\end{array}$ \\
\hline
\end{tabular}

Continua 


\begin{tabular}{|ll|}
\hline Iniciativas e projetos & Caracterização \\
\hline $\begin{array}{l}\text { Gestão por } \\
\text { competências }\end{array}$ & "Alguns estados estão promovendo a gestão por competências nas \\
& organizaç̃̃es por meio da certificação dos cargos públicos. Nesse processo \\
& os órgãos fazem o mapeamento das competências de determinado cargo e \\
& submetem os gestores públicos a processos seletivos para o recrutamento. \\
& A certificação busca definir, de maneira clara, as responsabilidades, \\
& competências individuais e a educação continuada dos cargos, contribuindo, \\
& assim, para a oferta de serviços de maior qualidade." \\
Planejamento & "Ainda é pouco utilizada a prática de se realizar o planejamento estratégico \\
estratégico & nos estados, de maneira conjunta entre os mais variados órgãos e gestores \\
& $\begin{array}{l}\text { para definir o plano com a direção, objetivos e metas que se pretende } \\
\text { alcançar. Essa iniciativa passou a ocorrer, por exemplo, no estado do Rio } \\
\text { de Janeiro, havendo sido considerada importante pelos gestores públicos } \\
\text { entrevistados." }\end{array}$ \\
\hline
\end{tabular}

Fonte: Dados da pesquisa

A partir da análise das iniciativas e dos projetos descritos no Quadro 2, evidencia-se, portanto, significativa proximidade com aqueles amplamente disseminados no âmbito das organizações privadas, como os programas de remuneração variável, os projetos de planejamento estratégico e de gestão de projetos e competências. Segundo os respondentes, parte da aprendizagem e execução de tais iniciativas encontra-se facilitada pela realização de parcerias com órgãos públicos, empresas de consultoria, escolas de negócios e organizações do terceiro setor. Para eles, a efetividade de tais projetos, depende, todavia, "de patrocinadores do processo, em especial, do empenho pessoal do governador e de seu secretariado". Isso, na medida em que a transformação requerida "demanda a administração de diversos conflitos, dependentes de vontade política, assim como de um discurso, de cima para baixo, que motive as pessoas a reorientarem seus valores e aspectos da cultura dos setores em que atuam".

\section{Especificidades da liderança na esfera pública}

Ao longo do levantamento empírico de dados, a temática da liderança emerge, em seus mais variados aspectos, como fator fundamental para a "transição a que passa a gestão pública brasileira".

Embora subjetiva e multifacetada, a definição de liderança apresenta certa convergência nos relatos dos executivos entrevistados. Na visão geral, a liderança encontra-se associada à capacidade do líder em "gerar sentido de coletividade em indivíduos do mesmo grupo, motivando pessoas a agirem em benefício comum". 
Quanto ao desenvolvimento da liderança, para grande parte dos respondentes, é possível desenvolvê-la. Alguns respondentes, no entanto, indicam que o "grande líder, aquele que se diferencia, que se destaca, apresenta atributos e características que são inatas e/ou adquiridas em sua criação". Para esses, o líder deve apresentar, acima de tudo, "vocação e perfil para exercer funções de liderança, que podem, apenas em parte, ser desenvolvidos".

Para tal desenvolvimento, mesmo que parcial, os respondentes indicam "cursos e programas de desenvolvimento, em seus vários níveis". Os executivos públicos pesquisados apontam que

as escolas têm a capacidade de identificar líderes em potencial, e representam importante meio de garantir a capacitação das pessoas na esfera pública. Entretanto, a formação de líderes ultrapassa a aprendizagem teórica, e os centros de ensino devem buscar desenvolver competências que estimulem a dimensão da prática e do relacionamento interpessoal.

A prática ou trajetória profissional dos gestores é, desse modo, enfatizada como fator preponderante ao desenvolvimento de competências de liderança: "Somente por meio da vivência em situações específicas, reais, é possível se experimentar a importância do exercício da liderança", argumenta um dos entrevistados. Nesse sentido, a diversidade de atividades, grupos e projetos desenvolvidos pelo individuo são apontados como elementos importantes ao desenvolvimento da liderança no setor. Para eles, ainda, "a nova geração, por estar exposta a diferentes contextos, redes e grupos, apresenta traços mais favoráveis à aceleração do processo de formação de novos líderes".

Vale ressaltar o entendimento, por parte da maioria dos entrevistados, de que a esfera pública, muito embora deva incorporar diversos princípios e lógicas do setor privado, demanda competências em liderança específicas. $\mathrm{Na}$ perspectiva dos respondentes, os gestores do setor privado parecem tender a terem maior "precaução na utilização dos recursos, com orientação constante para a redução de custos. Isso, na medida em que necessitam atender às expectativas dos acionistas, que são agentes mais tangíveis". O foco voltado para o lucro e, em maior grau, para resultados, também imprimiria, na perspectiva dos entrevistados, maiores pressões sobre a atuação dos gestores privados, requerendo competências particulares.

Na esfera pública, por sua vez, a perspectiva dos respondentes é que os líderes tenderiam a impor sua posição pelo cargo ocupado, não obstante reconhecerem a importância das lideranças informais. Sob a ótica dos pesquisados, diferentemente das organizações privadas, as lideranças do setor público devem lidar com maior multiplicidade de interesses, nem sempre formalmente 
explicitados, o que lhes "requer dar sentido e conduzir os caminhos trilhados pelos liderados". As equipes em órgãos públicos se apresentariam, assim, mais dependentes de seus líderes. Soma-se a isso a maior dificuldade de os líderes públicos em adotar mecanismos "relacionados à motivação de seus liderados, cujas carreiras são mais estáveis e inflexíveis considerando planos de carreira e remuneração", conforme anteriormente mencionado.

Finalmente, a partir da análise do conjunto das entrevistas constata-se a menção a diversos atributos de competência de liderança que caracterizariam o "líder público eficaz no contexto da nova gestão pública brasileira", conforme descritos no Quadro 3.

\section{Quadro 3}

\section{Competências requeridas ao líder público brasileiro contemporâneo}

\begin{tabular}{|c|c|}
\hline $\begin{array}{l}\text { Competências } \\
\text { requeridas ao } \\
\text { "líder eficaz" }\end{array}$ & Evidências \\
\hline $\begin{array}{l}\text { Capacidade de } \\
\text { Comunicação }\end{array}$ & $\begin{array}{l}\text { "Eu acho que o líder tem que formar uma boa equipe a partir de bons } \\
\text { profissionais. E a comunicação é fundamental para isso. A comunicação hoje, } \\
\text { além da oral, a eletrônica também, eu acho que é fundamental." }\end{array}$ \\
\hline $\begin{array}{l}\text { Capacidade de } \\
\text { lidar com os } \\
\text { liderados }\end{array}$ & $\begin{array}{l}\text { "Eu acho que uma capacidade de leitura das pessoas... Mas eu digo, de experiência } \\
\text { própria, eu não estou tentando generalizar, mas no que funcionou comigo até hoje, } \\
\text { é ler, tentar ler as pessoas, conhecê-las bem, para conseguir atuar de forma um } \\
\text { pouco diferente com cada uma, para obter às vezes o mesmo resultado." }\end{array}$ \\
\hline Legitimidade & $\begin{array}{l}\text { "Eu acho que coerência, legitimidade são os dois aspectos que eu destacaria. } \\
\text { Legitimidade para conduzir esse processo e coerência para envolver o grupo de } \\
\text { servidores que estão ao redor, para que a gente trabalhe de forma única." }\end{array}$ \\
\hline & $\begin{array}{l}\text { "Você tem que ser um líder que além de ser carismático, o carisma é sempre } \\
\text { bem-vindo, você vai ter que demonstrar bom-senso e competência. Para quê? }\end{array}$ \\
\hline Bom-senso & $\begin{array}{l}\text { Para isso legitimar o carisma, porque o carisma só, não se sustenta ao longo } \\
\text { do tempo, ele é muito bom no approach, mas depois, se você não tiver como } \\
\text { sustentar isso, ele não vai se sustentar." }\end{array}$ \\
\hline $\begin{array}{l}\text { Capacidade de } \\
\text { agregação }\end{array}$ & $\begin{array}{l}\text { "Então, a liderança do estado é mais agregadora. Ela precisa ser capaz de agregar } \\
\text { e chegar a seu fim, ter a sua persistência." }\end{array}$ \\
\hline Disciplina & $\begin{array}{l}\text { "Eu acho que o método e a disciplina nesse momento são muito importantes } \\
\text { para que você consiga. Claro que tem que ter qualidade, é o que eu digo, não } \\
\text { adianta ser um líder carismático. Além de você ter capacidade, você tem que ter } \\
\text { método. Eu acho que é por aí." }\end{array}$ \\
\hline Visão sistêmica & $\begin{array}{l}\text { "Ou seja, um gerente, um líder, aqui na nossa administração, tem que ter uma } \\
\text { visão sistêmica voltada, obviamente, para a situação do país, do mundo, mas } \\
\text { focado na área pública." }\end{array}$ \\
\hline Espírito de corpo & $\begin{array}{l}\text { "A liderança significa montar esse espírito de corpo, ter essa capacidade de moldar e } \\
\text { manter esse espírito de corpo. Que pessoas sempre acabam entrando em conflito." }\end{array}$ \\
\hline
\end{tabular}

Fonte: Dados da pesquisa 
Apesar de os termos liderança e gestão serem comumente confundidos, durante as análises buscou-se discernir quando os entrevistadores se referiam especificamente a cada um deles. Como resultado, pode-se identificar atributos de competências requeridos a gestores e a líderes (Quadros 1 e 3).

Ainda que existam convergências entre ambos os perfis, as características tidas como requeridas ao líder e aquelas demandadas ao gestor público indicam algumas diferenças. Uma delas parece ser que o líder, em comparação com o gestor, apresenta demandas por competências que "vão mais além da dimensão técnica", estando, mais amplamente, atreladas ao relacionamento com seus liderados e com os diversos stakeholders da instituição. Assim, como seria de se esperar, as competências dos líderes estão mais vinculadas às habilidades e atitudes, enquanto conhecimentos técnicos, fazem parte, em maior grau, das competências requeridas aos gestores.

Com base no conjunto de dados apresentados e analisados, passa-se, no item seguinte, a uma síntese dos achados e principais conclusões do estudo.

\section{Considerações finais}

Tendo como objetivo central investigar relações entre iniciativas que compõem o movimento em torno da chamada nova administração pública e o construto liderança foi possível agrupar os principais temas e desafios que caracterizam iniciativas nessa direção, empreendidos pelos estados de Minas Gerais e Rio de Janeiro, em cinco dimensões chave: O estágio atual do setor público brasileiro: a tônica na eficiência e em resultados; Desafios da transição para uma nova administração pública; Incorporação de políticas e práticas de gestão inspiradas no setor privado; Especificidades da liderança na esfera pública.

Tais achados, associados à análise de iniciativas e projetos desenvolvidos pelos estados pesquisados, direcionados a assegurar a "transição dos modelos tradicionais para este novo paradigma gerencial", revelam a introjeção e disseminação de práticas discursivas e dispositivos de gestão, com significativa influência de políticas e práticas amplamente disseminadas no meio empresarial. Além disso, revela-se evidente a utilização de tais iniciativas como bandeira e plataforma política, tendo por base o apelo positivo que noções como resultado e eficiência causam sobre a opinião pública e o eleitorado. Adicionalmente, ganhos imediatos, obtidos por meio de tais iniciativas, ao serem mais facilmente passíveis de mensuração e apresentação asseguram-lhes maior visibilidade, atribuindo aos seus executores imagens de competência e eficiência. 
O estudo permitiu, também, identificar competências individuais associadas ao gestor e líder do setor público, possibilitando, inclusive, algumas análises comparativas. Segundo os executivos entrevistados, entre as competências requeridas aos gestores públicos, face às demandas do contexto da nova administração pública, destacam-se: conhecimento da máquina pública, conhecimento jurídico, capacidade de promover o envolvimento da sociedade, capacidade de lidar com o público, objetividade, orientação para resultados, perspectiva global, relacionamento interpessoal e visão sistêmica. Já para o "líder eficaz" requerem-se atributos de competência, como: capacidade de comunicação, capacidade de lidar com os liderados, legitimidade, bom-senso, capacidade de agregação, disciplina, visão sistêmica e espírito de corpo (esprit de corps). Não obstante similaridades, as competências de liderança sugerem uma perspectiva mais articuladora das competências e recursos internos, assim como capacidade de atribuir aos liderados maior significado (raison d'être) e relevância de seus papéis. É curiosa, todavia, a ausência de menção a fatores éticos e àqueles associados à dimensão da sustentabilidade.

Tais achados revelam, no entanto, mudanças no perfil da gestão e das competências requeridas às lideranças do setor - em especial aquelas que se reconhecem e/ou são apontadas como "mais modernas" -, trazendo à tona a relevância de novas agendas nacionais de pesquisa sobre o setor e, em particular, sobre ações de desenvolvimento de lideranças aptas a lidar, de forma mais crítica, com os desafios, dicotomias e diásporas que marcam e/ou hão de caracterizar os contextos atual e futuro da gestão pública brasileira.

\section{Referências}

BRESSER PEREIRA, L.C. Da administração pública burocrática à gerencial. Revista do Serviço Público, v. 120, n. 1, p. 7-41, jan./abr. 1996.

BRESSER PEREIRA, L.C. Estratégia e estrutura para um novo Estado. Revista do Serviço Público, v. 124, n. 1, p. 5-25, jan./abr. 1997.

FAORO, R. Os donos do poder. São Paulo: Atlas, 1964.

FISCHER, T. Gestão do desenvolvimento e poderes locais: marcos teóricos e avaliação. Salvador: Casa da Qualidade, 2002.

FLICK, U. Introdução à pesquisa qualitativa. Porto Alegre: Artmed, 2009.

FLICK, Uwe. Introdução à pesquisa qualitativa. Porto Alegre: Artmed, 2009. 
FONSECA, Francisco César P. O curso de Administração Pública. FGV/81: percurso, sugestões e dilemas. Relatório de pesquisa 05. São Paulo: Eaesp/FGV, 2008.

GOFFEE, E.; JONES, G. Why should anyone be led by you? Harvard Business Review, p. 63-70, 2000.

HOOIJBERG, R.; CHOI, J. The impact of organizational characteristics on leadership effectiveness models: An examination of leadership in a private and a public sector organization. Administration \& Society, v. 33, p. 403-431, 2001.

LIPIETZ, A. Miragens e milagres: problemas da industrialização no terceiro mundo. São Paulo: Nobel, 1985.

MARTINS, H.F. Burocracia e a revolução gerencial: a persistência da dicotomia entre política e administração. Revista do Serviço Público, Brasília, v. 48, n. 1, p. 43-79, 1997.

MILES, M.B.; HUBERMAN, A.M. Qualitative data analysis. Cambridge: Cambridge University Press, 1994.

MOTTA, P.R. A modernização da administração pública brasileira nos últimos 40 anos. Revista de Administração Pública, Rio de Janeiro, p. 87-96, 2007.

PABLO, A.L. et al. Identifying, enabling and managing cynamic capabilities in the public sector. Journal of Management Studies, v. 44, n. 5, p. 687-708, 2007.

SARAIVA SILVA, L.A. Cultura organizacional em ambiente burocrático. RAC: Revista de Administração Contemporânea, n. 6, p. 187-207, 2002.

SILVA, C.E.S. Autonomia de gestão e concorrência: em busca de novas formas de gestão do setor público em um contexto pós-fordista. Revista de Administração Pública, Rio de Janeiro: v. 28, n. 3, p. 211-228, out./dez. 1994.

SCHEIN, E. Organizational culture and leadership. New York: Jossey \& Bass, 1992.

TERRY, L.D. Administrative leadership, neo-managerialism, and the public management movement. Public Administration Review, v. 58, n. 3, p. 194-200, 1998.

VAN WART, M. Public sector leadership theory: an assessment. Public Administration Review, v. 63, n. 2, p. 214-228, 2003. 